\title{
Considerations in the assessment of heart rate variability in biobehavioral research
}

\author{
Daniel S. Quintana ${ }^{1,2}{ }^{*}$ and James A. J. Heathers ${ }^{3}$ \\ ${ }^{1}$ NORMENT, K.G. Jebsen Centre for Psychosis Research, Institute of Clinical Medicine, University of Oslo, Oslo, Norway \\ 2 Division of Mental Health and Addiction, Oslo University Hospital, Oslo, Norway \\ ${ }^{3}$ School of Psychology, University of Sydney, Sydney, NSW, Australia
}

\section{Edited by:}

Andrew Kemp, Universidade de São

Paulo, Brazil

Reviewed by:

Mika Tarvainen, University of Eastern

Finland, Finland

George E. Billman, The Ohio State

University, USA

\section{${ }^{*}$ Correspondence:}

Daniel S. Quintana, NORMENT, K.G. Jebsen Centre for Psychosis

Research - TOP Study, Building 49, Oslo University Hospital, Ullevål,

Kirkeveien 166, P. O. Box 4956

Nydalen, 0424 Oslo, Norway

e-mail: daniel.quintana@medisin.

uio.no
Heart rate variability (HRV) refers to various methods of assessing the beat-to-beat variation in the heart over time, in order to draw inference on the outflow of the autonomic nervous system. Easy access to measuring HRV has led to a plethora of studies within emotion science and psychology assessing autonomic regulation, but significant caveats exist due to the complicated nature of HRV. Firstly, both breathing and blood pressure regulation have their own relationship to social, emotional, and cognitive experiments - if this is the case are we observing heart rate (HR) changes as a consequence of breathing changes? Secondly, experiments often have poor internal and external controls. In this review we highlight the interrelationships between $\mathrm{HR}$ and respiration, as well as presenting recommendations for researchers to use when collecting data for HRV assessment. Namely, we highlight the superior utility of within-subjects designs along with the importance of establishing an appropriate baseline and monitoring respiration.

Keywords: heart rate variability, autonomic nervous system, parasympathetic nervous system, psychophysiology, respiration, emotion

\section{THE USE OF HRV IN EMOTION SCIENCE AND PSYCHOLOGY}

The autonomic nervous system has been studied as a correlate of emotion for almost a century (Cannon, 1916). A central technique within this tradition of research is heart rate variability (HRV), which refers to a variety of methods for assessing the beat-to-beat change in the heart over time; these are used to approximate various aspects of autonomic outflow to the heart. Improvements in computing technology and miniaturization have made the electrocardiographic collection of inter-beat intervals (IBIs) accessible, and the analysis of the resulting beat-to-beat intervals trivial. One consequence of this access is a sustained interest in the application of HRV within the behavioral sciences, and in the psychology of emotion in particular. There are major biobehavioral theories that suggest that HRV can be used to investigate the central relationship between autonomic regulation and interpersonal interaction (Porges, 1995; Thayer and Lane, 2000). The neurovisceral integration model suggests that HRV is an index of the capacity for the central autonomic network (Benarroch, 1993) - which includes the brainstem, hypothalamus, and prefrontal cortex to adjust to environmental demands (Thayer and Lane, 2000). Porges' polyvagal theory takes a phylogenetic approach (i.e., it observes evolutionary and developmental commonalities within the structure and function of the vertebrate autonomic nervous system), arguing that social engagement is centrally facilitated by outflow and functional organization of vagus nerve (Porges, 1995). Consistent with this theory, reduced HRV has been observed in psychiatric disorders characterized by poor social cognition and emotion regulation (Bär et al., 2007; Quintana et al., 2013b). Interestingly, psychiatric patients also demonstrate less HRV reactivity during different levels of mental loading in comparison to healthy controls (Valkonen-Korhonen et al., 2003), further highlighting the poor cardiorespiratory regulatory capacity of this population.

While it may be the case that HRV can be used as a neurobiological index of interpersonal interaction, significant caveats exist due to the complicated nature of HRV and consequently uncertainty regarding what information is actually provided by common HRV indices (Berntson et al., 1997; Malpas, 2002; Billman, 2011). Additionally, the relationship between HRV and vagal modulation is complex in itself with a large interindividual variation (Picard et al., 2009). The problem is further compounded by the co-modulation of various respiratory and circulatory factors, which occur via numerous mechanisms and over multiple time-scales. Moreover, both breathing and blood pressure regulation have their own directly mediated relationships to the tasks employed in social, emotional, and cognitive experiments - if this is the case, we often have a complicated question of interlocking causalities. For instance, are observed changes in heart period epiphenomena that can be more parsimoniously described by changes in breathing or blood pressure? If the direction of causality between experimental task and the coordinated response within cardiac, circulatory, and respiratory variables is poorly understood, simple relationships between task and output changes may be obscured. Finally, experiments are often poorly designed as uncontrolled variables within typical experimental environments may drastically influence HRV. Few papers ideally control for medication, food, and water consumption, bladder filling, time of day, and other extraneous factors (Tak et al., 2009; Heathers, 2014). The overall aim of this review is to highlight the interrelationships between the nature and extraneous control of HRV, with a particular emphasis on respiration, and discuss implications for research in emotion science and psychology. Firstly, a number of 
important factors for the assessment of HRV in general and in emotion psychology in particular will be outlined. Secondly, solutions will be presented to reduce the potential impact of these factors.

\section{CAVEATS AND CONSIDERATIONS RESPIRATION IN HRV RESEARCH}

Coupling between respiration and heart rate (HR) has a long research history, and was noted in classical animal studies predating the electrocardiogram, which noticed fluctuations with breathing of heart beat and blood pressure (Ludwig, 1847). Consequently, the typically functioning respiratory system is presently characterized by complex breath-to-breath variations in respiratory rate and depth (Bruce, 1996) coupled with both heart period and blood pressure oscillations in a network of continual co-modification. For instance, a decrease in respiratory frequency generally corresponds with a lengthening of the heart period (Bruce, 1996). The traditional experimental approach of assessing the impact of the manipulation of one of these variables on another has led to important advancements in the understanding of cardiorespiratory coupling. However, perturbing the cardiorespiratory system does not allow the observation of casual relationships during spontaneous activity. Procedures developed to examine the coupling between time series may facilitate the identification of directionality and strength of cardiorespiratory coupling during spontaneous activity but these traditionally have only provided a limited insight into causality (e.g., Granger causality; Granger, 1969). Indeed, cardiorespiratory interaction has been variously quantified as primarily respiration-to-heart rate (Rosenblum et al., 2002; Zhu et al., 2013) heart rate-to-respiration (Larsen et al., 1999; Tzeng et al., 2003) or neither (i.e., bidirectional; Porta et al., 2013). These differences are likely to strongly depend on the analytical technique employed, but the details of this are unclear.

The nature of cardiorespiratory coupling is of intense research interest, highlighted most centrally by a robust debate concerning the central (Eckberg, 2009) and baroreflex (Karemaker, 2009) mechanism contributions to respiratory sinus arrhythmia (RSA). There is also a common genetic influence on HRV and respiration (Kupper et al., 2005). To further complicate this already complex relationship, the degree of cardiorespiratory coupling depends on the respiratory rate. That is, as the respiratory rate increases, HR increases phase distance from respiration. For instance, a breathing rate of 5-6 breaths per minute corresponds with a phase angle increase of $90^{\circ}$, continuing to a phase angle of $180^{\circ}$ with 10 breaths per minute (Angelone and Coulter, 1964). Indeed, a presumed tenet of RSA - that shorter R-R intervals should be coupled with the apogee of inspiration - only occurs at a slow respiratory rate of six breaths per minute (Vaschillo et al., 2004), around half the natural respiration rate. However, there is no relationship between cardiorespiratory coupling and baroreflex sensitivity or blood pressure variability (Tzeng et al., 2003).

Further, shared neural networks for respiratory and HR oscillations (Evans etal., 2009) suggest that the manipulation on breathing may also lead to unintended effects on HRV by removing some of the variance in HRV that may relevantly covary with experimental task. Intriguingly, the degree of coupling may be higher when HRV is increased and at lower breathing frequencies (Galletly and Larsen, 2001; Tzeng et al., 2003), suggesting that unhealthy populations or experiments that are designed to reduce HRV may be more prone to decoupling of cardiorespiratory oscillations. This observation is particularly relevant when comparing two populations that may display different breathing frequencies (e.g., anxious vs. non-anxious participants) or when an experimental manipulation modifies respiration. Notably, respiration is not a necessary condition to modify HR over time as variability is still observed (although significantly reduced) without mechanical respiratory input to the heart (Larsen et al., 1999). Conversely, individuals with no vagal input to the heart (e.g., heart transplant recipients) still demonstrate RSA (although to a much smaller degree) presumably due to mechanical effects on the sinoatrial node (Bernardi et al., 1989; Slovut et al., 1998). While respiration influences blood pressure via mechanical intrathoracic pressure changes, this is buffered by HRV (Toska and Eriksen, 1993; Elstad et al., 2001). The influence of respiration on blood pressure is likely to be caused by the mechanical influence on venous return, modulating cardiac output (Triedman and Saul, 1994) via changes in stroke volume, which in turn influences blood pressure (Elstad et al., 2001).

\section{THE IMPACT OF RESPIRATION DURING SOCIAL-EMOTIONAL TASKS}

Social-emotional tasks have been shown to reduce breathing variability (Vlemincx et al., 2011, 2012a), even for positively valenced emotions (Boiten, 1998), due to the "locked-in" attention often required during social-emotional tasks. Moreover, the mental stress that usually accompanies these tasks can also disorder general respiratory coordination (Vlemincx et al., 2012b). In addition to overall breathing variability, experimental stress induction can also influence the specific length of inspiration and expiration (Cohen et al., 1975). Thus, a social-emotional task that induces a change in respiratory time variables and/or depth may be indirectly influencing HRV. The rates of sighing also increase during these tasks (Vlemincx et al., 2011), with sighs shown to "reset" both respiratory variability and emotional states (Vlemincx et al., 2013). This is consistent with observations of increased sighing in a range of anxiety disorders (Abelson et al., 2001; Nardi et al., 2009), and increased sighing during experimentally induced stress (Vlemincx et al., 2012b). Finally, continual focused attention (e.g., during psychometrics tasks) has been shown in a number of studies (Mulder and Mulder, 1981; Aasman et al., 1987; Middleton et al., 1999) to reduce LF HRV, which creates further difficulties for interpretation.

There has been considerable debate on the necessity of controlling for respiration when assessing HRV. Denver et al. (2007) have argued against the need to control for respiration - at least for resting state recordings - given the important influence of breathing on HRV. To wit, by controlling for breathing in HRV recordings the researcher is removing an important influence on HRV (but see Grossman and Taylor, 2007). Denver et al. (2007) argue that if we assume that both respiration and heart beat oscillations are generated from the same central origin (e.g., Eckberg, 2009) then under resting state conditions controlling for respiration may not be necessary. Indeed, proponents for the control of respiration 
assume (either explicitly or implicitly) that alterations in respiratory frequency bring provoke HRV changes (i.e., the direction of causality moves from respiration to HR) without considering that HR adjustments may provoke changes in respiratory drive (Tzeng et al., 2003).

One compromise solution is to measure a participant's natural breathing rate, and use the derived frequency for respiratory pacing (e.g., Elstad, 2012). While this approach has utility during resting state registration, this procedure may inadvertently influence HRV during emotional or cognitive tasks as the participant has to consciously follow the pacing cue, in addition to paying attention to the experimental task - dual attention, in a number of contexts, significantly increases task difficulty (Pashler, 1994). Zhang et al. (2010) argue that cardiorespiratory coupling during a cognitive task can be influenced either by activation of the motor cortex, which deceases cardiorespiratory coupling, or via increases in SNS activity from completing a cognitive task. However, here sympathetic outflow was indexed by normalized low frequency HRV - which is not straightforwardly related to SNS activity (e.g., Grassi and Esler, 1999; Moak et al., 2007; Goedhart et al., 2008; Billman, 2011,2013a) - so this latter claim requires further empirical support using indices that more directly index cardiac sympathetic outflow.

Finally, slow respiratory rates (below $0.15 \mathrm{~Hz}$ ) hinder the reliable estimation of RSA given the overlap with the LF component, which can be an issue for physically fit individuals, or with experimentally induced relaxation. While the RSA peak can be visually identified on a person-to-person basis, an objective algorithm based on a continuous wavelet transform has been developed to select variable HF bandwidth based on the power spectrum of the respiratory signal (Goren et al., 2006).

\section{THE POORLY ADDRESSED NATURE OF HRV}

While the collection of raw interbeat interval data is relatively straightforward process, several lines of evidence suggest that ancillary and interpretative factors surrounding HRV receive insufficient attention.

(1) Heart rate variability is affected by respiratory depth (Hirsch and Bishop, 1981) and frequency (Angelone and Coulter, 1964; Brown et al., 1993). Specifically, greater RSA magnitude occurs during higher tidal volumes and lower respiratory frequencies. In addition, basal respiratory frequency has a non-linear relationship with spectral power as breathing rate falls below approximately $0.15 \mathrm{~Hz}$ (as it occasionally does in athletes; Saboul et al., 2014). Thus, any task that increases respiratory tidal volume and/or reduces respiratory frequency (e.g., meditation; Krygier etal., 2013), or conversely decreases tidal volume and/or increases respiratory frequency (e.g., mental stress; Houtveen et al., 2002) is likely to indirectly modify HRV. More recently, it has also been shown that the inspiration:expiration (I:E) ratio also effects HRV (Strauss-Blasche et al., 2000). Specifically, HRV increases when short inspiration is followed by long expiration - which has implications for tasks that require speech production (Cysarz etal., 2004) and many forms of meditation, for instance. Even monitoring spontaneous breathing has been found to reduce respiratory variability (Cysarz and Büssing, 2005; Conrad et al., 2007). HR driven cardiorespiratory coupling also appears to increase when HRV is higher (Galletly and Larsen, 2001).

(2) While respiration has been most typically studied as the dominant physiological rhythm relevant to HRV, much less in known about chemosensory (Berthoud and Neuhuber, 2000; Niewinski et al., 2014) and circadian (Furlan et al., 1990; Guo and Stein, 2002; Bonnemeier et al., 2003) influences.

(3) Heart rate variability continues to be used to form an index of putative autonomic outflow by measuring a point on a simple continuum of parasympathetic/sympathetic activity. While this model is still popular, it is directly at odds with a great deal of available evidence; for instance, that neuropeptide Y directly mediates transmission between adrenergic and muscarinic neurons (Revington and McCloskey, 1990). This approach, generally focused around the use of the LF/HF ratio (the ratio of low frequency power to high frequency power) to represent "sympathovagal balance," has been criticized extensively for over two decades (e.g., Eckberg, 1997; Billman, 2013a). This obscures the interpretation of HRV from the approximately $65 \%$ of papers which still report metrics in this manner (Heathers, 2014). While it is clear that LF power does not represent sympathetic activity (Goldstein etal., 2011) it is important to note that there has also been robust debate surrounding the relationship between HF power and parasympathetic activity (for a review see Billman, 2011).

(4) Differences in the prevailing HR can influence HRV both mathematically, due to the inverse curvilinear relationship between HR and RR interval (Sacha and Pluta, 2008) and physiologically, via the augmenting or diminishing effect of the autonomic constituent of HRV (Billman, 2013b). Consequently, emotional interventions that reduce PNS activation could inflate reductions in HRV via $\mathrm{HR}$ increases that are independent of changes in cardiac autonomic nerve activity. Nevertheless, it is possible to mathematically correct for the influence of the prevailing HR on HRV (Sacha, 2013; Pradhapan et al., 2014), which may also improve the reproducibility of HRV (Sacha et al., 2013).

Notwithstanding the evidence, these important caveats do not discourage research in the social and psychological sciences, which equate HRV variously as an index of emotional regulation (Appelhans and Luecken, 2006), stress response (Berntson and Cacioppo, 2004), and interpersonal engagement (Butler et al., 2006). Moreover, over 32 studies have specifically investigated the effect of emotion on HRV in healthy participants (Kreibig, 2010).

\section{THE NON-LINEAR NATURE OF HRV}

Frequency analysis assumes the $\mathrm{HR}$ signal is stationary (Stratonovich, 1967) and that over time it can be modeled as the sum of cyclical processes, but this is demonstrably not the case. While removing slow or DC trends from short periods of HRV will create a quasi-stationary series (e.g., Tarvainen et al., 2002), HRV in general displays the characteristics of a non-linear signal, given the biological origin and the origin of HRV deriving from sum of processes that operate on a variety of time scales (Winfree, 2001; Piskorski and Guzik, 2007; Stein et al., 2008). The non-linear interaction of the PNS and SNS systems may also contribute to heart beat complexity observed in healthy participants (Levy, 1971). 1/f-like scaling of the heart beat signal, which 
is characteristic of a heart beat series from a healthy individual (Ivanov et al., 1999; Goldberger et al., 2002), also points to a nonlinear basis. A $1 / f$ scaling of the heart beat signal $(\alpha=1)$ falls exactly between a completely random signal $(\alpha=0.5$; i.e., white noise) and an entirely predictable signal $(\alpha=1.5)$. For instance, pathological heart rhythms tend to demonstrate Brownian noise (Peng et al., 1995). A complex interaction of linear and non-linear systems contribute to HRV (Voss et al., 2009), which suggests that measures of complexity may be a better measure of autonomic nervous system outflow (Kaplan et al., 1991). Indeed, non-linear measures of HRV have demonstrated improved prognostic information in heart failure patients with in comparison to linear HRV measures (Bigger et al., 1996; Huikuri et al., 2000). However, the utility of non-linear HRV measures have been questioned due to a lack of reproducibility (Tan et al., 2009).

Intriguingly, non-linear analysis indicates that some elderly patients with cardiovascular disease unexpectedly display increased HRV indices (Stein et al., 2005) due to erratic, nonrespiratory sinus arrhythmia. These erratic rhythms have also been found to predict the onset of ventricular tachycardia (Mäkikallio et al., 1997) and mortality post-myocardial infarction (Stein et al., 2008). The source of this erratic non-respiratory sinus arrhythmia may be due to increased sympathetic activity (Tulppo et al., 1998), which is consistent with the higher concentrations of plasma noradrenaline observed in patients post-myocardial infarction (Christensen and Videbaek, 1974). Alternatively, erratic rhythms may be caused by poor coordination between the sinoatrial and atrioventricular nodes, which could reflect a pre-clinical manifestation of sick sinus syndrome (Stein et al., 2008).

A Poincaré plot is a visual, non-linear HRV index comprised of points that represent two consecutive heart periods, with any point above the identity line (a $45^{\circ}$ slope that passes through the origin, which represents equal consecutive heart periods) representing a longer heart period, whereas points below the identity line represent a shortening of the heart period. A healthy participant typically displays a "comet" shaped plot (Figure 1A), with a wider dispersion of points as the beats lengthen. Even at different rates of breathing (ranging from 6 to 16 breaths/min) this shape persists in healthy participants (Guzik et al., 2007). On the other hand, patients with heart failure display atypical "torpedo," "fan," or "complex" (i.e., stepwise clusters of points) patterns (Woo et al., 1992). A torpedo shape (Figure 1B) is indicative of a lack of $\mathrm{R}-\mathrm{R}$ interval increase when HR slows, whereas fan and complex patterns (Figure 1C) may represent general issues with cardiac autonomic regulation. Poincaré plots have been demonstrated to shown to display significant asymmetry in approximately $80 \%$ of individuals (Guzik et al., 2006; Piskorski and Guzik, 2007; Porta et al., 2008), with the plot "cloud" above the identity line appearing larger than the plot cloud below the line. Absent of longterm trends or very low frequency (VLF) power changes typically removed via detrending or high-pass filtering, HR acceleration will be matched with a roughly corresponding deceleration over time, and the Poincaré plots might be expected to be symmetrical. However, this commonly observed asymmetry in Poincaré plots suggests that HR accelerations operate in a different manner than decelerations, possibly due to baroreflex responses (Guzik et al., 2006). While the source of this asymmetry is unclear, it reinforces the fact that HRV is generated by complex non-linear dynamics. Together, this work emphasizes the importance of scrutinizing Poincaré plots for irregularities, particularly for populations characterized by low HRV (e.g., older participants), and urges caution with the central assumption that IBIs over time can be meaningfully devolved into the sum of sine waves as in traditional frequency-domain analysis.

\section{EXTERNAL FACTORS THAT CAN INFLUENCE HRV}

A number of external factors are usually controlled for in HRV research, including the intake of nicotine (Hayano et al., 1990; Sjoberg and Saint, 2011) and caffeine (Sondermeijer et al., 2002) preceding data collection. Cardioactive medication use, including some antidepressant classes (e.g., tricyclics; Kemp et al., 2010), some antipsychotic classes (e.g., clozapine; Cohen et al., 2001), benzodiazepines (Agelink et al., 2002), and antihypertensives (Schroeder et al., 2003) are also usually accounted for, although this may be somewhat difficult in practice when testing patient populations. Other factors that are usually accounted for include the time of day (Massin etal., 2000; van Eekelen et al., 2004), levels of habitual alcohol use (Quintana et al., 2013a,b),
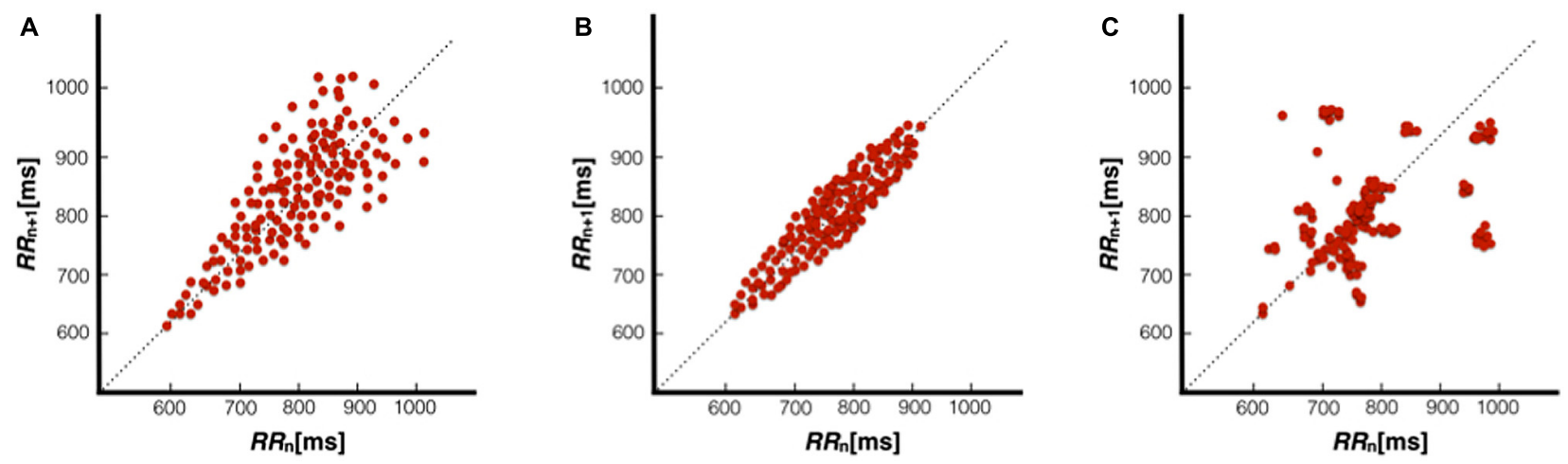

FIGURE 1 | Poincaré plots representative of a healthy individual with a comet pattern (A), heart failure patient with a torpedo pattern (B), and heart failure patient with a complex pattern (C). Figures adapted from Woo et al. (1992). 
physical activity levels (Britton et al., 2007; Soares-Miranda et al., 2014), and age (O'Brien et al., 1986). Digestion of food and water are less commonly accounted for in HRV research, but both provoke a coordinated autonomic response. For instance, digesting food has been shown to reduce parasympathetic activity, even an hour after eating a $500 \mathrm{kcal}$ meal (Lu et al., 1999). Even exposure to food-related cues elicits a similar response (Nederkoorn et al., 2000), suggesting a physiological response to the anticipation of a meal. Conversely, missing a meal (i.e., fasting) appears to have its own coordinated effects on HRV (Pivik et al., 2006), supporting the recommendation that participants consume a light meal approximately $2 \mathrm{~h}$ before the assessment of HRV (Tak et al., 2009). Water consumption has also been shown to increase HF-HRV in particular (Routledge et al., 2002), due to the vagal buffering response to the pressor effect provoked by hypo-osmotic fluids (Scott et al., 2001). Notably, this buffering response to the pressor effect is attenuated in older individuals (Jordan et al., 2000) and not observed in those with cardiac vagal denervation (Routledge et al., 2002). In addition, both bladder and gastric distension can also have an appreciable influence on HRV; these have been associated with increases in blood pressure and sympathetic outflow (Fagius and Karhuvaara, 1989; Rossi et al., 1998). However, papers only very rarely report that participants were asked to empty their bladder before experimental participation (Heathers, 2014).

\section{POTENTIAL METHODOLOGICAL CONTROLS WITHIN-SUBJECTS DESIGN OFFERS OPTIMAL EXPERIMENTAL CONTROL}

In light of the complex interactions described above, a withinsubjects design is the most appropriate method to explore the role of cardiorespiratory oscillations on behavior. Indeed, to appropriately detect a difference between groups, a sample size between 30 and 77, depending on the HRV metric used, is needed (Pinna et al., 2007). However, subgroups are commonly employed in these designs (e.g., gender, psychiatric comorbidities), which have been suggested to require 20 participants per cell (Simmons et al., 2011). Although some contexts make this difficult (i.e., comparison of psychiatric groups), within-subjects is the ideal design. The use of within-subjects design can eliminate any interindividual differences in coupling between HR, BP, and respiration. For instance, approximately $30 \%$ of individuals do not demonstrate any discernable synchrony between respiration and HR (Schäfer et al., 1998; Tzeng et al., 2003), with cardiorespiratory synchronization less likely to occur during higher breathing frequencies. While it is debatable if respiration should be controlled in HRV recordings, it is clear that sighs and long breaths have an effect on HRV as they generate non-sinus rhythm HR.

All of the caveats above can be minimized when individual comparisons are made between experimental points, that are as similar as possible. Most importantly, in the context of HRV, within-subjects designs better facilitate; (i) the removal of participants with atrial premature complexes and ventricular premature contractions, along with sighs, coughs, and gasps as such phenomena are easier to identify from multiple recordings if these are regular electrocardiographic errors or habitual behaviors; (ii) the elimination of individual differences in respiration rate, along with the avoidance of potential non-linear relationship of individual differences in respiration/HR relationship; (iii) the need for less participants (and consequently improved control over external variables due to repeat attendance under identical conditions); and (iv) a reduction in the impact of external factors such as medication, alcohol, nicotine, and recreational drug use.

\section{DEFINING A “RESTING STATE” OR BASELINE}

In an attempt to measure the effect of psychological task or group designation, much research assesses HRV during a resting state as a comparison to intervention. While informative, a more suitable method to interpret complex relationships between autonomic phenomena and psychological processes may be to perturb the cardiac autonomic system from complete rest. However, what constitutes a baseline needs to be carefully addressed depending on circumstances. A within-subjects experiment offers the most amount of control as a baseline is more likely to be similar.

Several caveats exist to the establishment of a baseline as an appropriate point of comparison. Firstly, the baseline HR needs to be able to support the respiratory signal without aliasing (Witte et al., 1988) - for instance, a normative breathing rate of $0.3 \mathrm{~Hz}$ can only be observed successfully in a $\mathrm{HR}$ faster than $0.6 \mathrm{~Hz}$ (i.e., $36 \mathrm{bpm}$ ). In a regular ECG, this criterion is often met. However, during supine recording, transient beats and intervals in healthy young people are frequently below $0.8 \mathrm{~Hz}$ (i.e., $48 \mathrm{bpm}$ ) - this may extend up to the entire IBI series in the case of physically fit individuals or any other participant displaying bradycardia. This corresponds with the fastest criterion for RSA in the HF-HRV band (i.e., $0.4 \mathrm{~Hz}$ ). While this is an abnormal situation (see Sacha and Grzeszczak, 2002), it is a potential confound to the establishment of a baseline, especially if IBI series are filtered incorrectly (Grossman and Taylor, 2007). Secondly, physically fit participants may not have sinus rhythm appropriate for analysis in the first instance due to potential changes to the sinoatrial node-hearts of such individuals have often been assumed to be slower at rest due to higher vagal tone but the balance of evidence does not presently favor this explanation (Boyett et al., 2013). However, the resumption of "normal" sinus rhythm may be observed during exercise, orthostatic stress, etc. - if this is an experimental condition, then the transition from resting baseline is affected. Thirdly, tasks often compare passive eyes-open rest as a baseline to the performance of a psychomotor, attentional, or emotional task, for instance. It is possible that this conflates the difference between passive rest vs. the act of paying attention to task with the difference between passive rest vs. the specific task demands of the experiment in question. A popular alternative to complete rest is the Vanilla baseline (Jennings et al., 1992), which requires subjects to perform a trivial counting task requiring sustained attention but minimal cognitive load, as opposed to what the authors term "enforced relaxation." Other similar approaches have been attempted (e.g., Piferi et al., 2000). Finally, with individual recordings made over time, there is the complicated situation of the immediacy of baseline-toexperiment transition. HR is not stable over time, and can exhibit non-periodic phenomena or bifurcations, which may be in conflict with the assumption that an initial baseline well reflects a later experimental condition. Researchers must also consider the potential effect of decay between tasks if cardiorespiratory effects 
are observed, what a normalization to baseline might look like, and of course the fact that secondary baselines may conflict with experimental instructions or manipulations. It is inherent from the above that an appropriate baseline is not a singular measurement with "correct" parameters under all circumstances, but rather the non-task situation that best controls for the presence of task comparison. In many situations, the comparison of a task to a "resting" state will therefore vary in appropriateness.

\section{MONITORING RESPIRATION}

As detailed above, basic changes in respiration can have a significant impact on HRV. Pneumotachography is the gold standard for the monitoring of tidal volume, however, the use of a closed face-mask required to do so is cumbersome and impractical for most research in emotion and psychological science (e.g., faceto-face interactions). In lieu of this, the use of a strain gage to index the expansion of the chest can give sufficient information most importantly, a strain gage can identify gross deviations of typical cyclical respiration (e.g., sighs, coughs). Mirroring the importance of HR measures to reflect true sinus rhythm (as an ectopic beat does not represent ANS input to the SA node), "true" respiratory cycles must also be used to correctly draw inference on respiratory oscillations and coupling to HR. However, signals from strain gages do not necessarily have a linear relationship of circumference to signal (i.e., distension/signal output relationships may be different at different belt tensions) and that chest circumference is itself an indirect measure of the respiratory cycle (i.e., lung and chest wall volumes are not identical). In lieu of direct respiratory measures, established algorithms (Moody et al., 1985, 1986) that have been successively improved (e.g., Park et al., 2008; Langley et al., 2010) can also provide an appropriate surrogate measure of respiration from based on ECG signal morphology.

There is at present no satisfying solution for a totally noninvasive monitoring of tidal volume but in the meantime it seems prudent to monitor respiration at least to identify gross errors from normal cardiorespiratory analysis assumptions. For instance, healthy participants occasionally breathe at frequencies slower than $0.15 \mathrm{~Hz}$ (up to $35 \%$ of participants; Hoit and Lohmeier, 2000; Beda et al., 2007; Pinna et al., 2007) - this has also been observed in physically fit individuals (Saboul et al., 2014). Breathing below $0.15 \mathrm{~Hz}$ dramatically increases the observed power of RSA over that of typical breathing frequencies due to the involvement of the baroreflex. Consequently, this will dramatically affect measures of LF-HRV, HF-HRV, total spectral power and any ratio between spectral bands (e.g., LF/HF or LFnu). However, any such participant can be easily identified from the unitless cyclical information provided by a strain gage, and subsequently discarded from analysis. Alternatively, it may be possible to remove the immediate effect of slow breathing cycles using a continuous wavelet approach (or any spectral analysis method that handles discontinuity well, such as an averaged lomb-scargle periodogram) to identify affected areas. Naturally, areas affected by slower breathing can be compared within subjects to periods of regular sinus rhythm (if available) to determine the level of distortion present in either spectral band. At present, we are not aware of any work that proposes an acceptable amount of distortion.

\section{CONCLUSION}

Enthusiasm for HRV within emotion science is subsequent to it being seen as a source of accurate, cheap, and non-invasive insight into autonomic outflow. This position should be strongly tempered by the present considerations. Instead, it would be more reasonable to say that HRV presents an admixture of insight and significant layers of complication. The behavior of the heart over time is the end-state of multiple interlocking systems, which present their own individual challenges for researchers at a cellular, local, and systemic level.

It should be mentioned here that while this paper focuses solely on issues of traditional methodological control, there are other domains in which significant improvements in the experimental environment surrounding HRV might be gained. Most crucially, signal analytic requirements often receive surprisingly little attention, and decisions about type of spectral analysis, windowing, and data cleaning are crucial (e.g., Berntson and Stowell, 1998) but are often under-reported. Likewise, recent interest in data uploading and retention (e.g., Nosek et al., 2012) has received little systematic attention in cardiac psychophysiology so far, even though a) data retention is a American Psychological Association requirement (American psychological association [APA], 2001) and b) the ability to broadly access raw data is a potentially excellent control for the methodological and analytical issues outlined here, as well as a test bed for the development of future HRV metrics and meta-analysis.

The best case scenario for the continuing use of HRV is that the significant challenges and complications provided by interrelationships most crucially between respiration and blood pressure are acknowledged, and that experimental designs are improved by appropriately accounting for common external factors known to aggressively modify HRV. Careful consideration of these factors will help ensure researchers use more accurate and reproducible measures of autonomic outflow.

\section{ACKNOWLEDGMENTS}

The authors thank Maja Elstad, Tobias Kaufmann, and Douglas Angus for helpful comments on an earlier version of this manuscript. They also thank the reviewers of this manuscript for their constructive comments.

\section{REFERENCES}

Aasman, J., Mulder, G., and Mulder, L. J. (1987). Operator effort and the measurement of heart-rate variability. Hum. Factors 29, 161-170. doi: 10.1177/001872088702900204

Abelson, J. L., Weg, J. G., Nesse, R. M., and Curtis, G. C. (2001). Persistent respiratory irregularity in patients with panic disorder. Biol. Psychiatry 49, 588-595. doi: 10.1016/S0006-3223(00)01078-7

Agelink, M. W., Boz, C., Ullrich, H., and Andrich, J. (2002). Relationship between major depression and heart rate variability. Clinical consequences and implications for antidepressive treatment. Psychiatry Res. 113, 139-149. doi: 10.1016/S0165-1781(02)00225-1

American psychological association [APA]. (2001). Publication Manual of the American Psychological Association. Washington, DC: American Psychological Association.

Angelone, A., and Coulter, N. A. (1964). Respiratory sinus arrhythmia: a frequency dependent phenomenon. J. Appl. Physiol. 19, 479-482.

Appelhans, B. M., and Luecken, L. J. (2006). Heart rate variability as an index of regulated emotional responding. Rev. Gen. Psychol. 10, 229. doi: 10.1037/10892680.10.3.229 
Bär, K. J., Boettger, M. K., Koschke, M., Schulz, S., Chokka, P., Yeragani, V. K., etal. (2007). Non-linear complexity measures of heart rate variability in acute schizophrenia. Clin. Neurophysiol. 118, 2009-2015. doi: 10.1016/j.clinph.2007.06.012

Beda, A., Jandre, F. C., Phillips, D. I., Giannella-Neto, A., and Simpson, D. M. (2007). Heart-rate and blood-pressure variability during psychophysiological tasks involving speech: influence of respiration. Psychophysiology 44, 767-778. doi: 10.1111/j.1469-8986.2007.00542.x

Benarroch, E. E. (1993). The central autonomic network: functional organization, dysfunction, and perspective. Mayo Clin. Proc. 68, 988-1001. doi: 10.1016/S00256196(12)62272-1

Bernardi, L., Keller, F., Sanders, M., Reddy, P., Griffith, B., Meno, F., et al. (1989). Respiratory sinus arrhythmia in the denervated human heart. J. Appl. Physiol. 67, 1447-1455.

Berntson, G. G., Bigger, J. T., Eckberg, D. L., Grossman, P., Kaufmann, P. G., Malik, M., et al. (1997). Heart rate variability: origins, methods, and interpretive caveats. Psychophysiology 34, 623-648. doi: 10.1111/j.1469-8986.1997.tb02140.x

Berntson, G. G., and Cacioppo, J. T. (2004). "Heart rate variability: stress and psychiatric conditions," in Dynamic Electrocardiography, eds M. Malik and A. J. Camm (New York, NY: Futura), 57-64.

Berntson, G. G., and Stowell, J. R. (1998). ECG artifacts and heart period variability: don't miss a beat! Psychophysiology 35, 127-132. doi: 10.1111/1469-8986.3510127

Berthoud, H.-R., and Neuhuber, W. L. (2000). Functional and chemical anatomy of the afferent vagal system. Auton. Neurosci. 85, 1-17. doi: 10.1016/S15660702(00)00215-0

Bigger, J. T., Steinman, R. C., Rolnitzky, L. M., Fleiss, J. L., Albrecht, P., and Cohen, R. J. (1996). Power law behavior of RR-interval variability in healthy middle-aged persons, patients with recent acute myocardial infarction, and patients with heart transplants. Circulation 93, 2142-2151. doi: 10.1161/01.CIR.93.12.2142

Billman, G. E. (2011). Heart rate variability - a historical perspective. Front. Physiol. 2:86. doi: $10.3389 /$ fphys.2011.00086

Billman, G. E. (2013a). The LF/HF ratio does not accurately measure cardiac sympatho-vagal balance. Front. Physiol. 4:26. doi: 10.3389/fphys.2013.00026

Billman, G. E. (2013b). The effect of heart rate on the heart rate variability response to autonomic interventions. Front. Physiol. 4:222. doi: 10.3389/fphys.2013.00222

Boiten, F. A. (1998). The effects of emotional behaviour on components of the respiratory cycle. Biol. Psychol. 49, 29-51. doi: 10.1016/S0301-0511(98)00025-8

Bonnemeier, H., Wiegand, U. K., Brandes, A., Kluge, N., Katus, H. A., Richardt, G., et al. (2003). Circadian profile of cardiac autonomic nervous modulation in healthy subjects. J. Cardiovasc. Electrophysiol. 14, 791-799. doi: 10.1046/j.15408167.2003.03078.x

Boyett, M. R., D’Souza, A., Zhang, H., Morris, G. M., Dobrzynski, H., and Monfredi, O. (2013). Viewpoint: is the resting bradycardia in athletes the result of remodeling of the sinoatrial node rather than high vagal tone? J. Appl. Physiol. 114, 1351-1355. doi: 10.1152/japplphysiol.01126.2012

Britton, A., Shipley, M., Malik, M., Hnatkova, K., Hemingway, H., and Marmot, M. (2007). Changes in heart rate and heart rate variability over time in middle-aged men and women in the general population (from the Whitehall II Cohort Study). Am. J. Cardiol. 100, 524-527. doi: 10.1016/j.amjcard.2007.03.056

Brown, T. E., Beightol, L. A., Koh, J., and Eckberg, D. L. (1993). Important influence of respiration on human RR interval power spectra is largely ignored. J. Appl. Physiol. 75, 2310-2317.

Bruce, E. N. (1996). Temporal variations in the pattern of breathing. J. Appl. Physiol. 80, 1079-1087.

Butler, E. A., Wilhelm, F. H., and Gross, J. J. (2006). Respiratory sinus arrhythmia, emotion, and emotion regulation during social interaction. Psychophysiology 43, 612-622. doi: 10.1111/j.1469-8986.2006.00467.x

Cannon, W. B. (1916). Bodily Changes in Pain, Hunger, Fear, and Rage: An Account of Recent Researches into the Function of Emotional Excitement. New York: Appleton.

Christensen, N. J., and Videbaek, J. (1974). Plasma catecholamines and carbohydrate metabolism in patients with acute myocardial infarction. J. Clin. Invest. 54, 278 286. doi: 10.1172/JCI107763

Cohen, H., Loewenthal, U., Matar, M., and Kotler, M. (2001). Association of autonomic dysfunction and clozapine: heart rate variability and risk for sudden death in patients with schizophrenia on long-term psychotropic medication. Br. J. Psychiatry 179, 167-171. doi: 10.1192/bjp.179.2.167

Cohen, H. D., Goodenough, D. R., Witkin, H. A., Oltman, P., Gould, H., and Shulman, E. (1975). The effects of stress on components of the respiration cycle. Psychophysiology 12, 377-380. doi: 10.1111/j.1469-8986.1975. tb00005.x

Conrad, A., Müller, A., Doberenz, S., Kim, S., Meuret, A. E., Wollburg, E., et al. (2007). Psychophysiological effects of breathing instructions for stress management. Appl. Psychophysiol. Biofeedback 32, 89-98. doi: 10.1007/s10484007-9034-x

Cysarz, D., and Büssing, A. (2005). Cardiorespiratory synchronization during Zen meditation. Eur. J. Appl. Physiol. 95, 88-95. doi: 10.1007/s00421-005-1379-3

Cysarz, D., Von Bonin, D., Lackner, H., Heusser, P., Moser, M., and Bettermann, H. (2004). Oscillations of heart rate and respiration synchronize during poetry recitation. Am. J. Physiol. Heart Circ. Physiol. 287, H579-H587. doi: 10.1152/ajpheart.01131.2003

Denver, J. W., Reed, S. F., and Porges, S. W. (2007). Methodological issues in the quantification of respiratory sinus arrhythmia. Biol. Psychol. 74, 286-294. doi: 10.1016/j.biopsycho.2005.09.005

Eckberg, D. L. (1997). Sympathovagal balance a critical appraisal. Circulation 96, 3224-3232. doi: 10.1161/01.CIR.96.9.3224

Eckberg, D. L. (2009). Point: counterpoint: respiratory sinus arrhythmia is due to a central mechanism vs. respiratory sinus arrhythmia is due to the baroreflex mechanism. J. Appl. Physiol. 106, 1740-1742. doi: 10.1152/japplphysiol.91107.2008

Elstad, M. (2012). Respiratory variations in pulmonary and systemic blood flow in healthy humans. Acta Physiol. 205, 341-348. doi: 10.1111/j.17481716.2012.02419.x

Elstad, M., Toska, K., Chon, K. H., Raeder, E. A., and Cohen, R. J. (2001). Respiratory sinus arrhythmia: opposite effects on systolic and mean arterial pressure in supine humans. J. Physiol. 536, 251-259. doi: 10.1111/j.1469-7793.2001.t01-1-00251.x

Evans, K. C., Dougherty, D. D., Schmid, A. M., Scannell, E., Mccallister, A., Benson, H., et al. (2009). Modulation of spontaneous breathing via limbic/paralimbicbulbar circuitry: an event-related fMRI study. Neuroimage 47, 961-971. doi: 10.1016/j.neuroimage.2009.05.025

Fagius, J., and Karhuvaara, S. (1989). Sympathetic activity and blood pressure increases with bladder distension in humans. Hypertension 14, 511-517. doi: 10.1161/01.HYP.14.5.511

Furlan, R., Guzzetti, S., Crivellaro, W., Dassi, S., Tinelli, M., Baselli, G., et al. (1990). Continuous 24-hour assessment of the neural regulation of systemic arterial pressure and RR variabilities in ambulant subjects. Circulation 81, 537547. doi: 10.1161/01.CIR.81.2.537

Galletly, D., and Larsen, P. (2001). Cardioventilatory coupling in heart rate variability: methods for qualitative and quantitative determination. Br. J. Anaesth. 87, 827-833. doi: 10.1093/bja/87.6.827

Goedhart, A. D., Willemsen, G., Houtveen, J. H., Boomsma, D. I., and De Geus, E. J. (2008). Comparing low frequency heart rate variability and preejection period: two sides of a different coin. Psychophysiology 45, 1086-1090. doi: 10.1111/j.14698986.2008.00710.x

Goldberger, A. L., Amaral, L. A., Hausdorff, J. M., Ivanov, P. C., Peng, C.-K., and Stanley, H. E. (2002). Fractal dynamics in physiology: alterations with disease and aging. Proc. Natl. Acad. Sci. U.S.A. 99, 2466-2472. doi: 10.1073/pnas. 012579499

Goldstein, D. S., Bentho, O., Park, M. Y., and Sharabi, Y. (2011). LF power of heart rate variability is not a measure of cardiac sympathetic tone but may be a measure of modulation of cardiac autonomic outflows by baroreflexes. Exp. Physiol. 96, 1255-1261. doi: 10.1113/expphysiol.2010.056259

Goren, Y., Davrath, L. R., Pinhas, I., Toledo, E., and Akselrod, S. (2006). Individual time-dependent spectral boundaries for improved accuracy in time-frequency analysis of heart rate variability. Biomed. Eng. IEEE Trans. 53, 35-42. doi: 10.1109/TBME.2005.859784

Granger, C. W. (1969). Investigating causal relations by econometric models and cross-spectral methods. Econometrica 37, 424-438. doi: 10.2307/1912791

Grassi, G., and Esler, M. (1999). How to assess sympathetic activity in humans. J. Hypertens. 17, 719-734. doi: 10.1097/00004872-199917060-00001

Grossman, P., and Taylor, E. W. (2007). Toward understanding respiratory sinus arrhythmia: relations to cardiac vagal tone, evolution and biobehavioral functions. Biol. Psychol. 74, 263-285. doi: 10.1016/j.biopsycho.2005.11.014

Guo, Y.-F., and Stein, P. K. (2002). Circadian rhythm in the cardiovascular system: considerations in non-invasive electrophysiology. Card. Electrophysiol. Rev. 6, 267-272. doi: 10.1023/A:1016337210738

Guzik, P., Piskorski, J., Krauze, T., Schneider, R., Wesseling, K. H., Wykretowicz, A., et al. (2007). Correlations between the Poincaré plot and conventional heart rate 
variability parameters assessed during paced breathing. J. Physiol. Sci. 57, 63-71. doi: 10.2170/physiolsci.RP005506

Guzik, P., Piskorski, J., Krauze, T., Wykretowicz, A., and Wysocki, H. (2006). Heart rate asymmetry by Poincaré plots of RR intervals. Biomed. Tech. 51, 272-275. doi: 10.1515/BMT.2006.054

Hayano, J., Yamada, M., Sakakibara, Y., Fujinami, T., Yokoyama, K., Watanabe, Y., et al. (1990). Short-and long-term effects of cigarette smoking on heart rate variability. Am. J. Cardiol. 65, 84-88. doi: 10.1016/0002-9149(90)90030-5

Heathers, J. A. (2014). Everything Hertz: methodological issues in short-term frequency-domain HRV. Front. Physiol. 5:177. doi: 10.3389/fphys.2014.00177

Hirsch, J. A., and Bishop, B. (1981). Respiratory sinus arrhythmia in humans: how breathing pattern modulates heart rate. Am. J. Physiol. Heart Circ. Physiol. 241, H620-H629.

Hoit, J. D., and Lohmeier, H. L. (2000). Influence of continuous speaking on ventilation. J. Speech Lang. Hear Res. 43, 1240-1251. doi: 10.1044/jslhr.4305.1240

Houtveen, J. H., Rietveld, S., and Geus, E. J. (2002). Contribution of tonic vagal modulation of heart rate, central respiratory drive, respiratory depth, and respiratory frequency to respiratory sinus arrhythmia during mental stress and physical exercise. Psychophysiology 39, 427-436. doi: 10.1111/1469-8986.3940427

Huikuri, H. V., Mäkikallio, T. H., Peng, C.-K., Goldberger, A. L., Hintze, U., and Møller, M. (2000). Fractal correlation properties of RR interval dynamics and mortality in patients with depressed left ventricular function after an acute myocardial infarction. Circulation 101, 47-53. doi: 10.1161/01.CIR.101.1.47

Ivanov, P. C., Amaral, L. A. N., Goldberger, A. L., Havlin, S., Rosenblum, M. G., Struzik, Z. R., et al. (1999). Multifractality in human heartbeat dynamics. Nature 399, 461-465. doi: 10.1038/20924

Jennings, J. R., Kamarck, T., Stewart, C., Eddy, M., and Johnson, P. (1992). Alternate cardiovascular baseline assessment techniques: vanilla or resting baseline. Psychophysiology 29, 742-750. doi: 10.1111/j.1469-8986.1992.tb02052.x

Jordan, J., Shannon, J. R., Black, B. K., Ali, Y., Farley, M., Costa, F., et al. (2000). The pressor response to water drinking in humans a sympathetic reflex? Circulation 101, 504-509. doi: 10.1161/01.CIR.101.5.504

Kaplan, D., Furman, M., Pincus, S., Ryan, S., Lipsitz, L., and Goldberger, A. (1991). Aging and the complexity of cardiovascular dynamics. Biophys. J. 59, 945-949. doi: 10.1016/S0006-3495(91)82309-8

Karemaker, J. M. (2009). Counterpoint: respiratory sinus arrhythmia is due to the baroreflex mechanism. J. Appl. Physiol. 106, 1742-1743. doi: 10.1152/japplphysiol.91107.2008a

Kemp, A. H., Quintana, D. S., Gray, M. A., Felmingham, K. L., Brown, K., and Gatt, J. M. (2010). Impact of depression and antidepressant treatment on heart rate variability: a review and meta-analysis. Biol. Psychiatry 67, 1067-1074. doi: 10.1016/j.biopsych.2009.12.012

Kreibig, S. D. (2010). Autonomic nervous system activity in emotion: a review. Biol. Psychol. 84, 394-421. doi: 10.1016/j.biopsycho.2010.03.010

Krygier, J. R., Heathers, J. A., Shahrestani, S., Abbott, M., Gross, J. J., and Kemp, A. H. (2013). Mindfulness meditation, well-being, and heart rate variability: a preliminary investigation into the impact of intensive Vipassana meditation. Int. J. Psychophysiol. 89, 305-313. doi: 10.1016/j.ijpsycho.2013.06.017

Kupper, N., Willemsen, G., Posthuma, D., De Boer, D., Boomsma, D. I., and De Geus, E. J. (2005). A genetic analysis of ambulatory cardiorespiratory coupling. Psychophysiology 42, 202-212. doi: 10.1111/j.1469-8986.2005.00276.x

Langley, P., Bowers, E. J., and Murray, A. (2010). Principal component analysis as a tool for analyzing beat-to-beat changes in ECG features: application to ECG-derived respiration. Biomed. Eng. IEEE Trans. 57, 821-829. doi: 10.1109/TBME.2009.2018297

Larsen, P., Trent, E., and Galletly, D. (1999). Cardioventilatory coupling: effects of IPPV. Br. J. Anaesth. 82, 546-550. doi: 10.1093/bja/82.4.546

Levy, M. N. (1971). Sympathetic-Parasympathetic Interactions in the Heart. Circ. Res. 29, 437-445. doi: 10.1161/01.RES.29.5.437

Lu, C.-L., Zou, X., Orr, W. C., and Chen, J. (1999). Postprandial changes of sympathovagal balance measured by heart rate variability. Dig. Dis. Sci. 44, 857-861. doi: 10.1023/A:1026698800742

Ludwig, C. (1847). Beiträge zur kenntniss des einflusses der respirationsbewegung auf den blutlauf im aortensystem. Arch. Anat. Physiol. 13, 242-302.

Mäkikallio, T. H., Seppänen, T., Airaksinen, K., Koistinen, J., Tulppo, M. P., Peng, C.-K., et al. (1997). Dynamic analysis of heart rate may predict subsequent ventricular tachycardia after myocardial infarction. Am. J. Cardiol. 80, 779-783. doi: 10.1016/S0002-9149(97)00516-X
Malpas, S. C. (2002). Neural influences on cardiovascular variability: possibilities and pitfalls. Am. J. Physiol. Heart Circ. Physiol. 282, H6-H20.

Massin, M. M., Maeyns, K., Withofs, N., Ravet, F., and Gérard, P. (2000). Circadian rhythm of heart rate and heart rate variability. Arch. Dis. Child. 83, 179-182. doi: 10.1136/adc.83.2.179

Middleton, H., Sharma, A., Agouzoul, D., Sahakian, B., and Robbins, T. (1999). Contrasts between the cardiovascular concomitants of tests of planning and attention. Psychophysiology 36, 610-618. doi: 10.1111/1469-8986.3650610

Moak, J. P., Goldstein, D. S., Eldadah, B. A., Saleem, A., Holmes, C., Pechnik, S., et al. (2007). Supine low-frequency power of heart rate variability reflects baroreflex function, not cardiac sympathetic innervation. Heart Rhythm 4, 1523-1529. doi: 10.1016/j.hrthm.2007.07.019

Moody, G. B., Mark, R. G., Bump, M. A., Weinstein, J. S., Berman, A. D., Mietus, J. E., et al. (1986). Clinical validation of the ECG-derived respiration (EDR) technique. Comput. Cardiol. 13, 507-510.

Moody, G. B., Mark, R. G., Zoccola, A., and Mantero, S. (1985). Derivation of respiratory signals from multi-lead ECGs. Comput. Cardiol. 12, 113-116.

Mulder, G., and Mulder, L. J. M. (1981). "Task-related cardiovascular stress," in Attention and Performance IX, eds J. Long and A. D. Baddeley (Hillsdale: Lawrence Erlbaum Associates), 591-606.

Nardi, A. E., Freire, R. C., and Zin, W. A. (2009). Panic disorder and control of breathing. Respir. Physiol. Neurobiol. 167, 133-143. doi: 10.1016/j.resp.2008.07.011

Nederkoorn, C., Smulders, F., and Jansen, A. (2000). Cephalic phase responses, craving and food intake in normal subjects. Appetite 35, 45-55. doi: 10.1006/appe. 2000.0328

Niewinski, P., Tubek, S., Banasiak, W., Paton, J. F., and Ponikowski, P. (2014). Consequences of peripheral chemoreflex inhibition with low-dose dopamine in humans. J. Physiol. 592(Pt 6), 1295-1308. doi: 10.1113/jphysiol.2012.266858

Nosek, B. A., Spies, J. R., and Motyl, M. (2012). Scientific utopia II. Restructuring incentives and practices to promote truth over publishability. Perspect. Psychol. Sci. 7, 615-631. doi: 10.1177/1745691612459058

O'Brien, I., O'Hare, P., and Corrall, R. (1986). Heart rate variability in healthy subjects: effect of age and the derivation of normal ranges for tests of autonomic function. Br. Heart J. 55, 348-354. doi: 10.1136/hrt.55.4.348

Park, S. B., Noh, Y. S., Park, S. J., and Yoon, H. R. (2008). An improved algorithm for respiration signal extraction from electrocardiogram measured by conductive textile electrodes using instantaneous frequency estimation. Med. Biol. Eng. Comput. 46, 147-158. doi: 10.1007/s11517-007-0302-y

Pashler, H. (1994). Dual-task interference in simple tasks: data and theory. Psychol. Bull. 116, 220-244. doi: 10.1037/0033-2909.116.2.220

Peng, C.-K., Havlin, S., Hausdorff, J., Mietus, J., Stanley, H., and Goldberger, A. (1995). Fractal mechanisms and heart rate dynamics: long-range correlations and their breakdown with disease. J. Electrocardiol. 28, 59-65. doi: 10.1016/S00220736(95)80017-4

Picard, G., Tan, C. O., Zafonte, R., and Taylor, J. A. (2009). Incongruous changes in heart period and heart rate variability with vagotonic atropine: implications for rehabilitation medicine. $P M R$ 1, 820-826. doi: 10.1016/j.pmrj.2009.07.017

Piferi, R. L., Kline, K. A., Younger, J., and Lawler, K. A. (2000). An alternative approach for achieving cardiovascular baseline: viewing an aquatic video. Int. J. Psychophysiol. 37, 207-217. doi: 10.1016/S0167-8760(00)00102-1

Pinna, G., Maestri, R., Torunski, A., Danilowicz-Szymanowicz, L., Szwoch, M., La Rovere, M., et al. (2007). Heart rate variability measures: a fresh look at reliability. Clin. Sci. 113, 131-140. doi: 10.1042/CS20070055

Piskorski, J., and Guzik, P. (2007). Geometry of the Poincaré plot of RR intervals and its asymmetry in healthy adults. Physiol. Meas. 28, 287-300. doi: 10.1088/09673334/28/3/005

Pivik, R., Dykman, R., Tennal, K., and Gu, Y. (2006). Skipping breakfast: gender effects on resting heart rate measures in preadolescents. Physiol. Behav. 89, 270280. doi: 10.1016/j.physbeh.2006.06.001

Porges, S. W. (1995). Orienting in a defensive world: mammalian modifications of our evolutionary heritage. A polyvagal theory. Psychophysiology 32, 301-318. doi: 10.1111/j.1469-8986.1995.tb01213.x

Porta, A., Casali, K. R., Casali, A. G., Gnecchi-Ruscone, T., Tobaldini, E., Montano, N., et al. (2008). Temporal asymmetries of short-term heart period variability are linked to autonomic regulation. Am. J. Physiol. Regul. Int. Comp. Physiol. 295, R550-R557. doi: 10.1152/ajpregu.00129.2008

Porta, A., Castiglioni, P., Di Rienzo, M., Bassani, T., Bari, V., Faes, L., et al. (2013). Cardiovascular control and time domain Granger causality: insights from 
selective autonomic blockade. Philos. Trans. Royal Soc. A Math. Phys. Eng. Sci. 371, 20120161. doi: 10.1098/rsta.2012.0161

Pradhapan, P., Tarvainen, M. P., Nieminen, T., Lehtinen, R., Nikus, K., Lehtimäki, T., et al. (2014). Effect of heart rate correction on pre- and post-exercise heart rate variability to predict risk of mortality - an experimental study on the FINCAVAS cohort. Front. Physiol. 5:208. doi: 10.3389/fphys.2014.00208

Quintana, D. S., Guastella, A. J., Mcgregor, I. S., Hickie, I. B., and Kemp, A. H. (2013a). Moderate alcohol intake is related to increased heart rate variability in young adults: implications for health and well-being. Psychophysiology 50, 1202-1208. doi: 10.1111/psyp.12134

Quintana, D. S., Mcgregor, I. S., Guastella, A. J., Malhi, G. S., and Kemp, A. H. (2013b). A Meta-analysis on the impact of alcohol dependence on short-term resting-state heart rate variability: implications for cardiovascular risk. Alcohol. Clin. Exp. Res. 37, E23-E29. doi: 10.1111/j.1530-0277.2012. 01913.x

Revington, M., and McCloskey, D. (1990). Sympathetic-parasympathetic interactions at the heart, possibly involving neuropeptide $\mathrm{Y}$, in anaesthetized dogs. J. Physiol. 428, 359-370.

Rosenblum, M. G., Cimponeriu, L., Bezerianos, A., Patzak, A., and Mrowka, R. (2002). Identification of coupling direction: application to cardiorespiratory interaction. Phys. Rev. E 65, 041909. doi: 10.1103/PhysRevE.65.041909

Rossi, P., Andriesse, G., Oey, P., Wieneke, G., Roelofs, J., and Akkermans, L. (1998). Stomach distension increases efferent muscle sympathetic nerve activity and blood pressure in healthy humans. J. Neurol. Sci. 161, 148-155. doi: $10.1016 / \mathrm{S} 0022-510 \mathrm{X}(98) 00276-7$

Routledge, H. C., Chowdhary, S., Coote, J. H., and Townend, J. N. (2002). Cardiac vagal response to water ingestion in normal human subjects. Clin. Sci. 103, 157162. doi: 10.1042/CS20010317

Saboul, D., Pialoux, V., and Hautier, C. (2014). The breathing effect of the LF/HF ratio in the heart rate variability measurements of athletes. Eur. J. Sport Sci. 14, S282-S288. doi: 10.1080/17461391.2012.691116

Sacha, J. (2013). Why should one normalize heart rate variability with respect to average heart rate. Front. Physiol. 4:306. doi: 10.3389/fphys.2013.00306

Sacha, J., and Grzeszczak, W. (2002). Remnants of respiratory peaks in heart rate variability spectrum of an adult man with tachypnea and bradycardia. Folia Cardiol. 9, 67-74.

Sacha, J., and Pluta, W. (2008). Alterations of an average heart rate change heart rate variability due to mathematical reasons. Int. J. Cardiol. 128, 444-447. doi: 10.1016/j.ijcard.2007.06.047

Sacha, J., Sobon, J., Sacha, K., and Barabach, S. (2013). Heart rate impact on the reproducibility of heart rate variability analysis. Int. J. Cardiol. 168, 4257-4259. doi: 10.1016/j.ijcard.2013.04.160

Schäfer, C., Rosenblum, M. G., Kurths, J., and Abel, H.-H. (1998). Heartbeat synchronized with ventilation. Nature 392, 239-240. doi: 10.1038/32567

Schroeder, E. B., Liao, D., Chambless, L. E., Prineas, R. J., Evans, G. W., and Heiss, G. (2003). Hypertension, blood pressure, and heart rate variability the Atherosclerosis Risk In Communities (ARIC) study. Hypertension 42, 1106-1111. doi: 10.1161/01.HYP.0000100444.71069.73

Scott, E. M., Greenwood, J. P., Gilbey, S. G., Stoker, J. B., and Mary, D. (2001). Water ingestion increases sympathetic vasoconstrictor discharge in normal human subjects. Clin. Sci. 100, 335-342. doi: 10.1042/CS20000177

Simmons, J. P., Nelson, L. D., and Simonsohn, U. (2011). False-positive psychology undisclosed flexibility in data collection and analysis allows presenting anything as significant. Psychol. Sci. 22, 1359-1366. doi: 10.1177/0956797611417632

Sjoberg, N., and Saint, D. A. (2011). A single $4 \mathrm{mg}$ dose of nicotine decreases heart rate variability in healthy nonsmokers: implications for smoking cessation programs. Nicotine Tob. Res. 13, 369-372. doi: 10.1093/ntr/ntr004

Slovut, D. P., Wenstrom, J. C., Moeckel, R. B., Wilson, R. F., Osborn, J. W., and Abrams, J. H. (1998). Respiratory sinus dysrhythmia persists in transplanted human hearts following autonomic blockade. Clin. Exp. Pharmacol. Physiol. 25, 322-330. doi: 10.1111/j.1440-1681.1998.tb02358.x

Soares-Miranda, L., Sattelmair, J., Chaves, P., Duncan, G., Siscovick, D. S., Stein, P. K., et al. (2014). Physical activity and heart rate variability in older adults: the cardiovascular health study. Circulation 129, 2100-2110. doi: 10.1161/CIRCULATIONAHA.113.005361

Sondermeijer, H. P., Van Marle, A. G., Kamen, P., and Krum, H. (2002). Acute effects of caffeine on heart rate variability. Am. J. Cardiol. 90, 906-907. doi: $10.1016 / \mathrm{S} 0002-9149(02) 02725-\mathrm{X}$
Stein, P. K., Domitrovich, P. P., Hui, N., Rautaharju, P., and Gottdiener, J. (2005). Sometimes higher heart rate variability is not better heart rate variability: results of graphical and nonlinear analyses. J. Cardiovasc. Electrophysiol. 16, 954-959. doi: $10.1111 / j .1540-8167.2005 .40788 . x$

Stein, P. K., Le, Q., and Domitrovich, P. P. (2008). Development of more erratic heart rate patterns is associated with mortality post-myocardial infarction. J. Electrocardiol. 41, 110-115. doi: 10.1016/j.jelectrocard.2007.11.005

Stratonovich, R. L. (1967). Topics in the Theory of Random Noise. New York: Gordon and Breach.

Strauss-Blasche, G., Moser, M., Voica, M., Mcleod, D., Klammer, N., and Marktl, W. (2000). Relative timing of inspiration and expiration affects respiratory sinus arrhythmia. Clin. Exp. Pharmacol. Physiol. 27, 601-606. doi: 10.1046/j.14401681.2000.03306.x

Tak, L. M., Riese, H., De Bock, G. H., Manoharan, A., Kok, I. C., and Rosmalen, J. G. (2009). As good as it gets? A meta-analysis and systematic review of methodological quality of heart rate variability studies in functional somatic disorders. Biol. Psychol. 82, 101-110. doi: 10.1016/j.biopsycho.2009.05.002

Tan, C. O., Cohen, M. A., Eckberg, D. L., and Taylor, J. A. (2009). Fractal properties of human heart period variability: physiological and methodological implications. J. Physiol. 587, 3929-3941. doi: 10.1113/jphysiol.2009.169219

Tarvainen, M. P., Ranta-aho, P. O., and Karjalainen, P. A. (2002). An advanced detrending method with application to HRV analysis. IEEE Trans. Biomed. Eng. 49, 172-175. doi: 10.1109/10.979357

Thayer, J. F., and Lane, R. D. (2000). A model of neurovisceral integration in emotion regulation and dysregulation. J. Affect. Disord. 61, 201-216. doi: 10.1016/S01650327(00)00338-4

Toska, K., and Eriksen, M. (1993). Respiration-synchronous fluctuations in stroke volume, heart rate and arterial pressure in humans. J. Physiol. 472, 501-512.

Triedman, J. K., and Saul, J. P. (1994). Blood pressure modulation by central venous pressure and respiration. Buffering effects of the heart rate reflexes. Circulation 89, 169-179. doi: 10.1161/01.CIR.89.1.169

Tulppo, M. P., Mäkikallio, T. H., Seppänen, T., Airaksinen, J. K. E., and Huikuri, H. V. (1998). Heart rate dynamics during accentuated sympathovagal interaction. Am. J. Physiol. Heart Circ. Physiol. 274, H810-H816.

Tzeng, Y. C., Larsen, P. D., and Galletly, D. C. (2003). Cardioventilatory coupling in resting human subjects. Exp. Physiol. 88, 775-782. doi: 10.1113/eph8802606

Valkonen-Korhonen, M., Tarvainen, M. P., Ranta-Aho, P., Karjalainen, P. A., Partanen, J., Karhu, J., et al. (2003). Heart rate variability in acute psychosis. Psychophysiology 40, 716-726. doi: 10.1111/1469-8986.00072

van Eekelen, A. P., Houtveen, J. H., and Kerkhof, G. A. (2004). Circadian variation in cardiac autonomic activity: reactivity measurements to different types of stressors. Chronobiol. Int. 21, 107-129. doi: 10.1081/CBI-120027983

Vaschillo, E., Vaschillo, B., and Lehrer, P. (2004). Heartbeat synchronizes with respiratory rhythm only under specific circumstances. Chest J. 126, 1385-1387. doi: 10.1378/chest.126.4.1385-a

Vlemincx, E., Abelson, J. L., Lehrer, P. M., Davenport, P. W., Van Diest, I., and Van Den Bergh, O. (2013). Respiratory variability and sighing: a psychophysiological reset model. Biol. Psychol. 93, 24-32. doi: 10.1016/j.biopsycho.2012.12.001

Vlemincx, E., Diest, I., and Bergh, O. (2012a). Imposing respiratory variability patterns. Appl. Psychophysiol. Biofeedback 37, 153-160. doi: 10.1007/s10484-0129187-0

Vlemincx, E., Van Diest, I., and Van Den Bergh, O. (2012b). A sigh following sustained attention and mental stress: effects on respiratory variability. Physiol. Behav. 107, 1-6. doi: 10.1016/j.physbeh.2012.05.013

Vlemincx, E., Taelman, J., De Peuter, S., Van Diest, I., and Van Den Bergh, O. (2011). Sigh rate and respiratory variability during mental load and sustained attention. Psychophysiology 48, 117-120. doi: 10.1111/j.1469-8986.2010.01043.x

Voss, A., Schulz, S., Schroeder, R., Baumert, M., and Caminal, P. (2009). Methods derived from nonlinear dynamics for analysing heart rate variability. Philos. Trans. Royal Soc. A Math. Phys. Eng. Sci. 367, 277-296. doi: 10.1098/rsta.2008.0232

Winfree, A. T. (2001). The Geometry of Biological Time. New York: Springer. doi: 10.1007/978-1-4757-3484-3

Witte, H., Zwiener, U., Rother, M., and Glaser, S. (1988). Evidence of a previously undescribed form of respiratory sinus arrhythmia (RSA) - the physiological manifestation of "cardiac aliasing". Pflügers Arch. 412, 442-444. doi: 10.1007/BF01907565

Woo, M. A., Stevenson, W. G., Moser, D. K., Trelease, R. B., and Harper, R. M. (1992). Patterns of beat-to-beat heart rate variability in advanced 
heart failure. Am. Heart J. 123, 704-710. doi: 10.1016/0002-8703(92) 90510-3

Zhang, J., Yu, X., and Xie, D. (2010). Effects of mental tasks on the cardiorespiratory synchronization. Respir. Physiol. Neurobiol. 170, 91-95. doi: 10.1016/j.resp.2009.11.003

Zhu, Y., Hsieh, Y.-H., Dhingra, R. R., Dick, T. E., Jacono, F. J., and Galán, R. F. (2013). Quantifying interactions between real oscillators with information theory and phase models: application to cardiorespiratory coupling. Phys. Rev. E 87, 022709. doi: 10.1103/PhysRevE.87.022709

Conflict of Interest Statement: The authors declare that the research was conducted in the absence of any commercial or financial relationships that could be construed as a potential conflict of interest.
Received: 06 June 2014; accepted: 07 July 2014; published online: 22 July 2014. Citation: Quintana DS and Heathers JAJ (2014) Considerations in the assessment of heart rate variability in biobehavioral research. Front. Psychol. 5:805. doi: 10.3389/ fpsyg.2014.00805

This article was submitted to Emotion Science, a section of the journal Frontiers in Psychology.

Copyright (c) 2014 Quintana and Heathers. This is an open-access article distributed under the terms of the Creative Commons Attribution License (CC BY). The use, distribution or reproduction in other forums is permitted, provided the original author(s) or licensor are credited and that the original publication in this journal is cited, in accordance with accepted academic practice. No use, distribution or reproduction is permitted which does not comply with these terms. 